\title{
Number of New Bone Lesions
}

National Cancer Institute

\section{Source}

National Cancer Institute. Number of New Bone Lesions. NCI Thesaurus. Code C132464.

A measurement of the total number of bone tumors that have not been previously seen or characterized. 